\title{
Relation between cytokines and routine laboratory data in children with septic shock and purpura
}

\author{
J. A. Hazelzet ${ }^{1}$, E. van der Voort ${ }^{1}$, J. Lindemans ${ }^{2}$, P.G. J. ter Heerdt ${ }^{2}$, H. J. Neijens ${ }^{3}$ \\ ${ }^{1}$ Department of Pediatrics, Division of Pediatric Intensive Care, Sophia Children's Hospital, Erasmus University, Rotterdam, The Netherlands \\ ${ }^{2}$ Department of Clinical Chemistry, Sophia Children's Hospital, Erasmus University, Rotterdam, The Netherlands \\ ${ }^{3}$ Department of Pediatrics, Division of Pediatric Infectious Diseases, Sophia Children's Hospital, Erasmus University, Rotterdam, \\ The Netherlands
}

Received: 2 March 1993/Accepted: 31 August 1993

\begin{abstract}
Objective: To establish the relation between routine laboratory data (lactate, fibrinogen, CRP) and cytokines (TNF,IL-1 and -6) and to estimate their prognostic value in pediatric patients with severe infectious purpura on admission.
\end{abstract}

Design: Prospective study.

Setting: Pediatric intensive care unit (PICU).

Patients: 17 children aged 5-172 months (median 46) were hospitalized in our PICU in 1989-90 with severe infectious purpura. Neisseria meningitidis was isolated in 15 children and Haemophilus influenzae in two. The patients were divided into 3 groups: non-shock, shock and severe shock leading to death. Shock was defined by standard criteria.

Measurements: Arterial blood was sampled for lactate, CRP, fibrinogen, TNF, and IL-1 and -6 on admission. The PRISM (pediatric risk of morality)-score was recorded.

Methods: Statistical analysis was performed with the Student's $t$-test using the logarithmic values of the cytokine concentration, and Spearman correlation analysis.

Results: According to the shock criteria, 9 patients were in shock of whom 4 did not survive. Significant differences existed between the 3 groups concerning lactate, TNF, and IL-6. Fibrinogen, CRP, IL-1, and PRISM-score discriminated only between survivors and non-survivors. A highly significant correlation existed between cytokines, the PRISM-score and lactate (TNF: $r=0.69$, IL-1: $r=0.56$, IL-6: $r=0.65$, PRISM: $r=0.65$ ). A significant inverse correlation existed between cytokines and CRP (TNF: $r=-0.55$, IL-1: $r=-0.64$, and IL-6: $r=-0.56)$, and IL-6 and fibrinogen $(r=-0.65)$.

Conclusion: These results show a significant correlation between cytokines and lactate, and lactate, TNF and IL-6 are closely associated with the severity of septic shock with purpura in children.

Presented in part at the 5th European Symposium on Pediatric, Surgical and Neonatal Intensive Care, October 8-11, 1991, Madrid, Spain

Correspondence to: J.A. Hazelzet, MD, Dr. Molewaterplein 60, NL-3015 GJ Rotterdam, The Netherlands
Key words: Purpura - Septic shock - Meningococcal infections - Cytokines - Lactate - Prognostic factors

Septic shock combined with purpura is a clinical syndrome with a sudden onset and a rapid progression. Most patients are children under the age of 10 years and the infection is mostly caused by meningococci. The severity of the clinical condition on admission to hospital and the progression of the disease may be difficult to estimate. For this reason several scoring systems including laboratory data have been proposed to predict the prognosis of the disease. Recently Leclerc et al. [1] presented a study in which they indicated that there was a good correlation between the serum C-reactive protein (CRP) level and the prognosis of children with severe infectious purpura and shock. Giraud et al. [2] showed that in 35 adult patients with meningococcal purpura, low fibrinogen level $(1.5 \mathrm{~g} / \mathrm{l})$ was the sole variable with prognostic value.

During the last decade a new group of proteins, called cytokines, has been identified as important mediators of the host response to sepsis. Most extensively studied are probably Tumor Necrosis Factor (TNF) and Interleukin 1 (IL-1), especially in relation to meningococcal infections [3-6]. More recently it has become clear that another cytokine, Interleukin 6 (IL-6), is also involved in the systemic changes during severe infections [7]. The biological activities of IL- 6 partly overlap those of IL -1 and TNF, but IL- 6 is probably also involved in the regulation of TNF and IL-1 production [8]. IL-6 is secreted by macrophages, fibroblasts, and endothelial cells, it stimulates the synthesis of acute-phase proteins and is an endogenous pyrogen.

During acute admission of a patient with septic shock laboratory data are routinely determined to estimate the clinical condition of the patient, for instance: lactate as end-product of anaerobic metabolism, a marker of cellular hypoxia; C-reactive protein (CRP), an acute-phase protein as marker for inflammation and tissue injury and fibrinogen, an acute-phase protein and coagulation factor. 
The aims of this study were to investigate the relation between cytokines and these established laboratory indices on admission and the association of these to the severity of the disease. This relation so far, has not been studied in children with septic shock and purpura.

\section{Patients and methods}

The study protocol was approved by the Institutional Review Board, and this Board waved the need for informed consent.

\section{Patients}

The patients who were studied were all admitted to the Pediatric Intensive Care Unit from the Sophia Children's Hospital in Rotterdam with the suspicion of severe infectious purpura, i.e. a clinical diagnosis of sepsis (manifested by 2 or more of the following conditions: temperature $>38.5^{\circ} \mathrm{C}$ or $<36^{\circ} \mathrm{C}$; heart rate above $2 \mathrm{SD}$ of the age related mean normal value; respiratory rate $>25 / \mathrm{min}$ and white blood cell count $>12000 / \mathrm{mm}^{3}$ or $<4000 / \mathrm{mm}^{3}$, in combination with petechiae and/or purpura. The patients were divided into a shock group and a non-shock group according to standard criteria (two or more of the following features: systolic blood pressure below $2 \mathrm{SD}$ of the age-related mean normal value, diuresis less than $0.8 \mathrm{ml} / \mathrm{kg} / \mathrm{h}$, capillary refill time more than $3 \mathrm{~s}$, need for inotropic support, sudden change in mental state). The PRISM-score [9] was recorded using the most abnormal value of each variable recorded in the first $4 \mathrm{~h}$ after admission.

\section{Assays}

On admission arterial blood was sampled as soon as possible: $1 \mathrm{ml}$ was collected in fluoride-oxalate for measurement of lactate, $1 \mathrm{ml}$ was taken in citrate for determination of fibrinogen, $2 \mathrm{ml}$ were allowed to clot and serum stored at $-70^{\circ} \mathrm{C}$ for measurement of cytokines and CRP in a later stage.

Lactate was measured by enzymatic end-point determination [10], CRP by immuno-nephelometric assay [11], and fibrinogen by standard procedures [12]. TNF and IL-1 were measured using an immunoradiometric assay for quantative measurement (IRMA, Medgenix Diagnostics Benelux), and IL- 6 by using an enzyme amplified sensitivity immuno-assay (EASIA, Medgenix Diagnostics Benelux). These assays measure free and receptor-complexed cytokines.

\section{Statistical analysis}

Differences between patient groups were analyzed using the unpaired two-tailed Student's $t$-test with separate variance estimation. The logarithmic values of the cytokine concentrations were used in this test. Relationships of cytokines to other laboratory data were determined by calculating the Spearman correlation coefficient and a two-tailed significance.

\section{Results}

From August 1989 untill July 1990 there were 17 patients who fulfilled the criteria. In 15 patients Neisseria meningitidis and in 2 patients Haemophilus influenza were isolated in blood and/or cerbrospinal fluid. Inotropic support was started in only one patient within $0.5 \mathrm{~h}$ before admission and in the other patients when necessary after admission.

According to the defined citeria 9 patients were in shock of whom 4 did not survive. The latter 4 patients were considered as a separate group.

The values of lactate, fibrinogen, CRP, TNF, IL-1, and IL-6 for the different groups are presented in Fig. 1.
Significant differences existed between all 3 groups concerning lactate, TNF, and IL-6. Fibrinogen, CRP and IL-1 discriminated only between survivors and non-survivors. Regarding the PRISM-scores, there were only significant $(p<0.01)$ differences between survivors $(10.1 \pm 6)$ and non-survivors $(30.5 \pm 10)$.

A highly significant correlation (Table 1) existed between cytokines, the PRISM-score and lactate (TNF: $r=0.69$, IL-1: $r=0.56$, IL-6: $r=0.65$, PRISM: $r=0.65$ ). A significant inverse correlation existed between cytokines and CRP (TNF: $r=-0.55$, IL-1: $r=-0.64$, and IL-6: $r=-0.56$ ), and IL-6 and fibrinogen $(r=-0.65)$. No significant correlations were found between TNF, IL-1, PRISM and fibrinogen, and PRISM and CRP.

\section{Discussion}

Septic shock with purpura is a life threatening clinical syndrome with an overwhelming course and is frequently fatal. Most often it is caused by severe meningococcal disease (SMD) and the highest incidence is found in children under the age of 10 years. In the Netherlands the attack rate of meningococcal sepsis has increased from 100 cases in 1986 to 320 in 1991 on a total number of 15 million inhabitants. This increase has also been reported in other countries in Europe. On admission it is not always easy to estimate the severity of the clinical situation. Nevertheless, one has to decide on the necessity for aggressive therapy and the level of supportive care. As we are more and more aware, septic shock is initiated by peripheral cellular alterations that lead to systemic dysfunction and organ failure. Some of these functional alterations may be caused directly by the infectious organisms or their products. An important portion of the pathogenesis however is mediated by endogenous host factors, particularly cytokines [3]. In clinical studies, especially in SMD, the presence and concentration of TNF, IL-1, and IL- 6 in serum turned out to be related to severity of disease and survival $[2,4-7,13-16]$. Also the results in this study confirm the existence of a clear relation between the serum levels of TNF and IL-6 and both severity and survival of pediatric SMD-patients. A practical drawback of cytokines is the time required for the performance of the assays, taking several hours or even a day. Routine laboratory indices like lactate, CRP and fibrinogen are easier and much faster to determine, but their relation to the level of cytokines and the severity of the disease have not been completely elucidated in SMD. Lactate, an endproduct of anaerobic metabolism and in this way a marker of cellular dysfunction and tissue hypoperfusion [17], proved in this study to correlate well with severity of disease. Most of the studies regarding lactate in critically ill patients are in agreement with these results [7, 17, 18]. However in a recently published study no significant difference in lactate was found between survivors and nonsurvivors in septic patients [19].

In our study a negative correlation was found between CRP-level and severity of disease with a significant difference between survivors and non-survivors. This is in agreement with the study of Leclerc [1]. Other clinical 

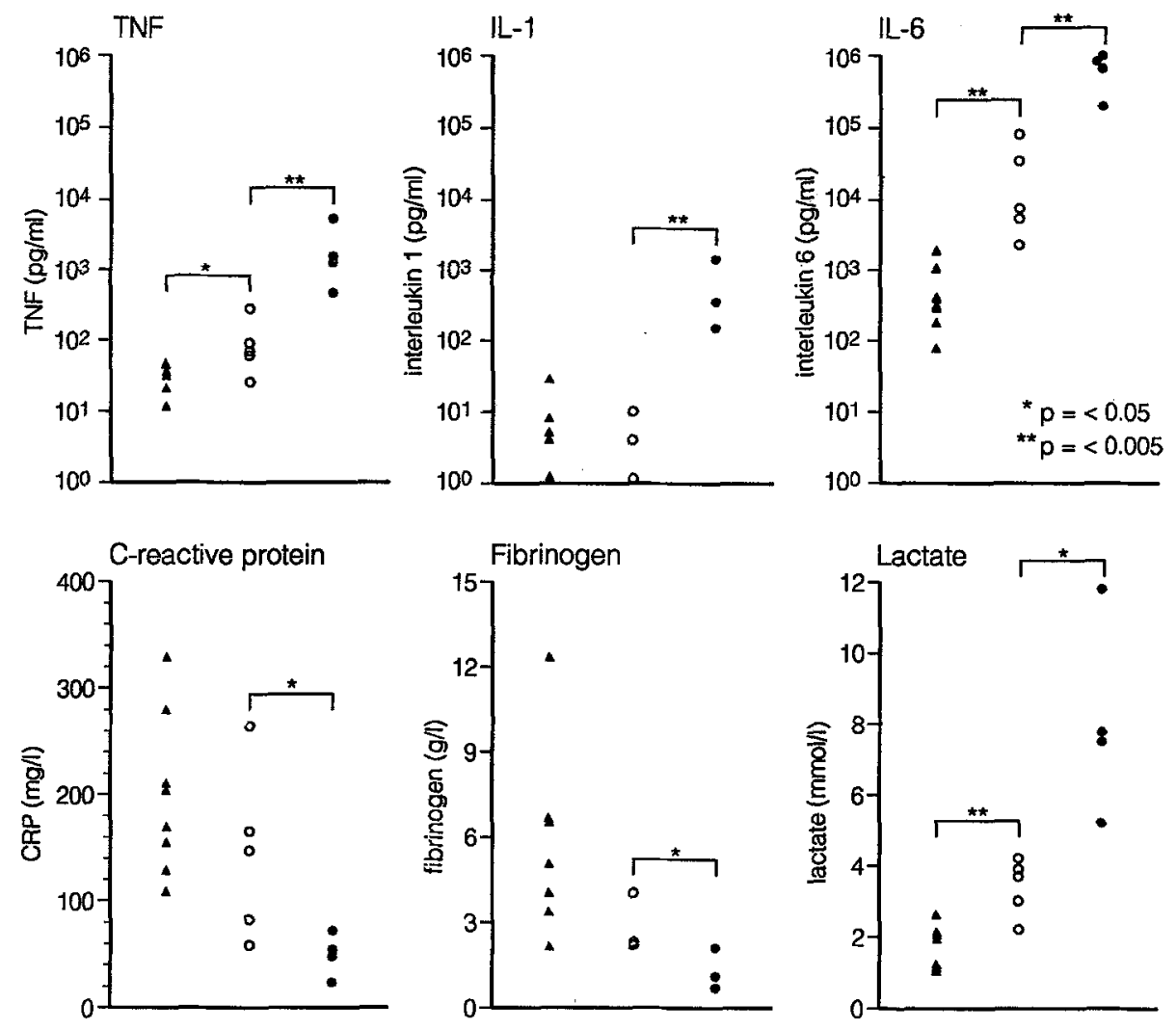

Fig. 1. Serum concentrations for cytokines (TNF, IL-1, and IL-6) and routine laboratory data (CRP, fibrinogen, and lactate) on admission for the 3 groups (triangles represent non-shock patients, open circles shock patients who survived, and the closed cir. cles are shock patients who did not survive

studies on septic shock patients [7, 19], burn patients [15, 20], and experimental studies [13], have presented positive correlations between CRP or other acute phase proteins and survival. CRP has been demonstrated to bind to damaged tissue in vivo. When bound, CRP is capable of activating the complement system via the classical pathway [20]. In addition, CRP stimulates the secretion of TNF, IL-1, IL-6, resulting in a self-amplifying inflammatory sequence $[3,20]$ and in this way plays a critical role in the inflammatory response to infection and injury. Nevertheless, a negative correlation between CRP and the level of cytokines was found. An explanation for this phenomenon might be either that CRP is massively bound in the initial phase of the illness or the fact that CRP may not yet have had enough time to increase in severe SMD. Peltola [21] described a group of patients with epiglottitis in whom the CRP level was related to the duration of the history. Leclerc found no relation between CRP level and the time between measurement and onset of symptoms [1].

Table 1. Non-linear correlation-coefficients (Spearman) between routine laboratory parameters, PRISM-score and cytokines, and linear correlation coefficients between laboratory parameters and PRISM-score

\begin{tabular}{lllll}
\hline & Lactate & CRP & Fibrinogen & PRISM \\
\hline TNF & $0.71^{* *}$ & $-0.50^{*}$ & -0.43 & $0.66^{* *}$ \\
IL-1 & $0.56^{*}$ & $-0.64^{* *}$ & -0.05 & 0.49 \\
IL-6 & $0.67^{* *}$ & $-0.51^{*}$ & $-0.65^{*}$ & $0.79 * *$ \\
PRISM & $0.65^{* *}$ & -0.50 & -0.57 & - \\
\hline
\end{tabular}

$* p=0.05, * * p=0.01, * * * p=0.001$
We found significant differences in the fibrinogen level between survivors and non-survivors. There was a negative, non-significant correlation between fibrinogen and cytokines. These results are also described in other studies $[2,4]$. Fibrinogen is an acute phase protein, which is increased during infections and inflammation. It is an important clotting factor and the level is decreased during diffuse intravascular coagulation (DIC). In SMD the level of fibrinogen probably reflects more the severity of the DIC, than the extent of the acute phase protein reaction.

The serum levels of cytokines and lactate correlated well with the PRISM-score, which in another way suggests their relation with the severity of the disease.

A log-linear, positive relation exists between cytokines and arterial plasma lactate in children with septic shock and purpura. In this condition we observed a negative, exponential relation between cytokines and CRP, and fibrinogen on admission. Cytokines, as well as lactate, CRP and fibrinogen have a good prognostic value for survival. However lactate, TNF and IL-6 correlate significantly with the PRISM-score and differentiate also for the severity of the disease. These variables can be used to select patient groups for the use of new therapeutic modalities, to follow the effect of these therapies, and to compare patient groups.

\section{References}

1. Leclerc F, Chenaud M, Delepoulle F, Francois DJ, Alain M, Valerie $H$ (1991) Prognostic value of C-reactive protein level in severe infectious purpura: a comparison with eight other scores. Crit Care Med 19:430-432 
2. Giraud T et al. (1991) Adult overwhelming meningococcal purpura. Arch Intern Med 151:310-316

3. Cannon JG (1991) Cytokines and shock. In: Cytokines and inflammation. CRC Press, Florida, pp 307-329

4. Girardin E, Grau GE, Dayer JM, Roux-Lombard P, Lambert PH (1988) Tumor necrosis factor and interleukin-1 in the serum of children with severe infectious purpura. N Engl J Med 319:397-400

5. Damas P, Aimee R, Gysen P, Demonty J, Lamy M, Franchimont $P$ (1989) Tumor necrosis factor and interleukin-1 serum levels during severe sepsis in humans. Crit Care Med 17:975-978

6. Waage A, Brandtzaeg P, Halstensen A, Kierulf P, Espevik T (1989) The complex pattern of cytokines in serum from patients with meningococcal septic shock. Association between interleukin 6, interleukin 1, and fatal outcome. J Exp Med 169:333-338

7. Hack CE et al. (1989) Increased plasma levels of interleukin-6 in sepsis. Blood 74:1704-1710

8. Schindler R, Mancilla J, Endres S, Ghorbani R, Clark SC, Dinarello CA (1990) Correlations and interactions in the production of interleukin-6 (IL-6), IL-1, and tumor necrosis factor (TNF) in human blood mononuclear cells: IL-6 suppresses IL-1 and TNF. Blood 75:40-147

9. Pollack M, Ruttiman U, Getson P (1988) Pediatric risk of mortality (PRISM) score. Crit Care Med 16:1110-1116

10. Marbach E, Weil M (1967) Rapid enzymatic measurement of blood lactate and pyruvate. Clin Chem 13:314-325

11. Sternberg J (1977) A rate nephelometer for measuring specific proteins by immunoprecipitation reaction. Clin Chem 23:1456- 1464
12. Clauss A (1957) Gerinnungsphysiologische Schnellmethode zur Bestimmung des Fibrinogens. Acta Haematol 17:237

13. Fony Y et al. (1989) Endotoxemia elicits increased circulating beta 2-IFN/IL-6 in man. J Immunol 142:2321-2324

14. Cannon JG et al. (1990) Circulating interleukin-1 and tumor necrosis factor in septic shock and experimental endotoxin fever. J Infect Dis 161:79-84

15. Nijsten MW, de Groot ER, ten Duis HJ, Klasen HJ, Hack CE, Aarden LA (1987) Serum levels of interleukin-6 and acute phase responses [letter]. Lancet II:p 921

16. Sullivan JS, Kilpatrick L, Costarino ATJ, Lee SC, Harris MC (1992) Correlation of plasma cytokine elevations with mortality rate in children with sepsis. J Pediatr 120:510-515

17. Mizock BA, Falk JL (1992) Lactic acidosis in critical illness. Crit Care Med 20:80-93

18. Rashkin MC, Bosken C, Baughman RP (1985) Oxygen delivery in critically ill patients. Relationship to blood lactate and survival. Chest 87:580-584

19. Dofferhoff AS et al. (1992) Patterns of cytokines, plasma endotoxin, plasminogen activator inhibitor, and acute-phase proteins during the treatment of severe sepsis in humans. Crit Care Med 20:185-192

20. Yamada $Y$ et al. (1990) Cytokines, acute phase proteins, and tissue injury, C-reactive protein opsonizes dead cells for debridement and stimulates cytokine production. Ann NY Acad Sci 587:351-361.

21. Peltola H, Jaakkola M (1988) C-reactive protein in early detection of bacteremic versus viral infections in immunocompetent and compromised children. J Pediatr 113:641-646 